\title{
'E não nos deixeis cair em tentação': livros de leitura religiosa do governo fascista para as escolas italianas no Brasil (anos 20 e 30 do século XX)
}

'And lead us not into temptation': religious reading books from the fascist government to italian schools in Brazil (1920s and 1930s of the XX century)

'Y no nos dejes caer en tentación': libros de lectura religiosa del gobierno fascista para las escuelas italianas en Brasil (años 20 y 30 del siglo XX)

\author{
Terciane Ângela Luchese \\ Universidade de Caxias do Sul (Brasil) \\ https://orcid.org/0000-0002-6608-9728 \\ http://lattes.cnpq.br/7640634913198342 \\ taluches@ucs.br
}

\section{RESUMO}

O presente texto analisa produção, circulação e estratégias de (con)formação postos em jogo pelos dois volumes do livro Letture di Religione, distribuídos gratuitamente aos alunos das escolas italianas do Brasil. A presença dessas escolas no país foi considerável e em 1908, contabilizava-se 13.657 alunos que frequentavam 264 instituições, sendo 13 católicas. A rede consular responsabilizava-se pela recepção e distribuição de materiais escolares (predominantemente livros) e subsídios financeiros da Itália para o Brasil. Com o Fascismo, intensificou-se a organização e a atenção às escolas. Ancorada nos referenciais da História Cultural, o corpus empírico é formado por livros escolares, legislações, jornais e relatórios consulares, sendo a análise documental histórica o procedimento metodológico. Compreender os saberes produzidos e difundidos pelo uso dos referidos livros como propagadores do ideal fascista e católico nas escolas italianas do exterior e os sentidos simbólicos que esses objetos adquiriram no universo escolar é tema de relevância para a História da Educação.

PALAVRAS-CHAVE: Livros escolares; Escolas italianas no Brasil; Ensino religioso. 


\begin{abstract}
The present text analyzes the production, circulation and strategies of (con) formation put in play by the two volumes of the book Letture di Religione, distributed free to students of Italian schools in Brazil. The presence of these schools in the country was considerable and in 1908, there were 13,657 students attending 264 institutions, of which 13 were Catholic. The consular network was responsible for receiving and distributing school supplies (predominantly books) and financial subsidies from Italy to Brazil. With Fascism, organization and attention to schools intensified. Anchored in the Cultural History references, the empirical corpus consists of school books, legislations, newspapers and consular reports, and historical documentary analysis was the methodological procedure. Understanding the knowledge produced and disseminated by the use of these books as propagators of the fascist and catholic ideal in Italian schools abroad and the symbolic meanings that these objects acquired in the school universe is a theme of relevance for the History of Education.
\end{abstract}

KEYWORDS: School books; Italian schools in Brazil; Religious education.

\title{
RESUMEN
}

El presente texto analiza producción, circulación y estrategias de (con)formación puestas en juego por los dos volúmenes del libro Letture di Religione, distribuidos gratuitamente a los alumnos de las escuelas italianas de Brasil. La presencia de esas escuelas en el país fue considerable y en 1908, se contabilizaba 13657 alumnos que frecuentaban 264 instituciones, siendo 13 católicas. La red consular se responsabilizaba por la recepción y distribución de materiales escolares (predominantemente libros) y subsídios financieros de Italia para Brasil. Con el Fascismo, se intensificó la organización y la atención a las escuelas. Anclado en las referencias de la Historia Cultural, el corpus empírico está formado por libros escolares, legislaciones, periódicos e informes consulares, siendo el procedimiento metodológico análisis documental histórico. Comprender los saberes producidos y difundidos por el uso de los referidos libros como propagadores del ideal fascista y católico en las escuelas italianas del exterior y los sentidos simbólicos que esos objetos adquirieron en el universo escolar es tema relevante para la Historia de la Educación.

PALABRAS CLAVE: Libros escolares; Escuelas italianas en Brasil; Educación religiosa. 


\section{Considerações iniciais}

Ao iniciar o ano de 1934, em fevereiro, o aluno Nicolino Murino assinava a primeira página do seu livro de Letture di Religione. Nicolino era aluno da $3^{\mathrm{a}}$ classe elementar do Instituto Manzoni ${ }^{1}$, em São Paulo. As anotações ordinárias de Nicolino ${ }^{2}$ e o livro sobreviveram por décadas e chegam à contemporaneidade como portadores de possibilidades investigativas para o campo da História da Educação. O presente texto é resultado da pesquisa "História das culturas escolares nas escolas italianas em terras brasileiras (1875 - 1945)", financiada pelo CNPq e que nesse recorte tem como objetivo analisar a produção, a circulação e as estratégias de (con)formação postos em jogo pelos dois volumes do livro Letture di Religione, distribuídos gratuitamente aos alunos das escolas italianas do Brasil.

Os dois volumes de Letture di Religione são parte de um conjunto de livros didáticos produzidos e enviados gratuitamente para serem distribuídos aos alunos das escolas italianas no exterior, modo como eram nominadas as escolas étnicas no período fascista. Livros de leitura, de aritmética, de geografia, de história pátria, de cantos, de literatura e outros foram enviados. Nesse texto, o olhar investigativo centra-se na análise dos dois volumes de Letture de Religione, obras escritas e compiladas por Giuseppe Fanciulli, importante autor italiano para a literatura infanto-juvenil dessa época. $\mathrm{O}$ primeiro volume é dedicado à classe segunda e terceira, enquanto que o segundo é dirigido à quarta e quinta classe.

Ancorada nos referenciais da História Cultural, o corpus empírico é formado por livros escolares, legislações e relatórios consulares, sendo a análise documental o procedimento metodológico que orienta o olhar investigativo. O texto foi organizado em três momentos: no primeiro contextualiza-se as escolas italianas no exterior atentando para o caso brasileiro, sua relação com o Fascismo e a Igreja Católica, no segundo apresenta-se uma breve biografia do autor dos livros analisados para, no terceiro momento, atentar-se para a produção, a materialidade das obras e sua circulação nas escolas italianas no Brasil.

\footnotetext{
${ }^{1}$ O Instituto Alexandre Manzoni estava situado na R. José Paulino, $\mathrm{n}^{\circ}$ 101, bairro Bom Retiro e era dirigido pelo professor Antônio Pratola. Nos anos 1930, anexo ao instituto, funcionava a Escola de Comércio Tiradentes. Em nota no jornal Correio Paulistano de 08/01/1930, n p. 07, lê-se: "Nos cursos diurnos do Instituto Alexandre Manzoni as aulas começaram, regularmente, ontem. Os cursos preparatórios noturnos começarão a funcionar no dia 13 do corrente. Na Escola de Comércio Tiradentes as aulas reabrir-se-ão no dia 3 de fevereiro próximo. Estão abertas as matrículas para os cursos diurnos e para as diversas classes comerciais. A entrega das carteiras escolares, contendo as provas escritas bimestrais do ano passado serão entregues aos alunos do Instituto Manzoni nos dias 8 e 9 do corrente." (CORREIO PAULISTANO, 08/01/1930, p. 07). Em 1936, o Correio Paulistano (08/08/1936, p. 04) noticia que "O Instituto Manzoni, um dos mais antigos estabelecimentos de ensino da capital, a título de encorajamento, oferece em cada bimestre aos melhores alunos do curso elementar prêmios em livros, certificados de louvor, etc.” O Instituto Manzoni era uma escola 'italiana', mas que passou por processos de adaptação mediante as exigências legais das políticas de nacionalização, negociando questões curriculares e de organização da escola. Cabe destacar que se em dezembro de 1927 o cônsul da Itália, Dr. Barbarisi havia assistido aos exames finais e ficado satisfeito com os resultados e o progresso dos alunos (CORREIO PAULISTANO, 24/12/1927, p. 16). Mas em 24 de dezembro de 1937 a inspeção dos exames finais foi realizada pelo Prof. Casimiro Ferreira da Rocha (CORREIO PAULISTANO, 24/12/1936, p. 12). Outro destaque que merece ser feito é que em visita a São Paulo, o embaixador da Itália, Victor Cerutti visitou o Instituto Mazoni em 03 de dezembro de 1930 (Jornal A Gazeta, 03/12/1930, p. 12). Há registros elogiosos sobre o trabalho do diretor, imigrado da Itália, Antônio Pratola.

${ }_{2}^{2}$ Nicolino Murino foi aluno do Instituto Manzoni e depois também da Escola de Comércio Tiradentes, aparecendo como aprovado no primeiro ano propedêutico no ano letivo de 1936, conforme noticiado pelo Correio Paulistano (CORREIO PAULISTANO, 01/01/1937, p. 17).
} 


\section{1 - Escolas italianas no exterior, Fascismo e Igreja}

Em textos anteriores afirmo que o processo escolar entre imigrantes saídos da península itálica e estabelecidos no Brasil entre o final do século XIX e primeiras décadas do século XX, vivenciaram experiências escolares étnicas nas diferentes unidades federativas que se estabeleceram (Luchese 2012, 2014, 2015). Grosso modo, podemos dizer que os imigrantes buscaram a escola pública, mas pelas dificuldades que o próprio Estado brasileiro enfrentou para oferecer escolas em número e condições para esses contingentes populacionais, fez com que os mesmos abrissem escolas étnicas. Assim, "nos diferentes espaços, na pluralidade de condições, num amplo processo de negociação, tensionamento e disputa, contingenciados, inclusive, por legislações provinciais diversas [...] produziram e foram produzidos por práticas educativas, marcadamente étnicas" (LUCHESE, 2014, p. 17). Nos estados de Espírito Santo, Pernambuco, Minas Gerais, Rio de Janeiro, São Paulo, Paraná, Santa Catarina e Rio Grande do Sul encontram-se registros de escolas étnicas abertas em áreas rurais, muitas delas comunitárias e também escolas étnicas mantidas por associações de mútuo socorro, essas, em geral, nas áreas urbanas. Ainda, escolas confessionais e particulares com marcas étnicas. Conforme dados apresentados por Parlagrecco em 1906, conforme quadro a seguir, eram 171 escolas italianas que atendiam mais de dez mil alunos, uma quantidade relativamente pequena, comparando-se com o número de crianças e jovens imigrantes e descendentes, mas que não pode ser ignorada.

Quadro 1 - Escolas italianas no Brasil - 1905 - 1906

\begin{tabular}{|l|c|c|}
\hline Estado & Escolas italianas & Total de alunos \\
\hline Pernambuco & 1 & 35 \\
\hline Rio de Janeiro & 3 & 316 \\
\hline Espírito Santo & 4 & 200 \\
\hline Minas Gerais & 4 & 277 \\
\hline Paraná & 7 & 526 \\
\hline São Paulo & 92 & 6.131 \\
\hline Rio Grande do Sul & 28 & 1.941 \\
\hline Santa Catarina & 32 & 1.519 \\
\hline Total & $\mathbf{1 7 1}$ & $\mathbf{1 0 . 9 4 5}$ \\
\hline
\end{tabular}

Fonte: FANFULLA, 1906, p. $800-802$.

Poucos anos depois, em 1908, por exemplo, foram contabilizados 13.657 alunos que frequentavam 264 escolas italianas, sendo 13 delas católicas (MINISTERO, 1908). As escolas italianas no exterior eram, desde 1870, responsabilidade do Ministério das Relações Exteriores da Itália. Portanto, a rede consular era a responsável pelo envio sistemático de relatórios que expunham as condições das escolas italianas nos diversos países que tinham presença de emigrantes. Eram os cônsules também os responsáveis pela recepção e distribuição de materiais escolares (predominantemente livros) e subsídios financeiros, que, com oscilações, foram remetidos aos diversos países que contavam com a presença de escolas italianas. 
Com o advento fascista, intensificou-se a organização e a atenção às escolas italianas no exterior. Legislações específicas sobre seleção e produção dos livros e materiais didáticos a serem distribuídos gratuitamente aos alunos passaram a ser frequentes. A organização didático-curricular única, as exigências quanto aos docentes e suas competências foram normatizadas. Os livros, que desde fins do século XIX eram enviados e distribuídos nos consulados, avolumaram-se e qualificaram-se. Como destaca Salvetti (2009), a principal ação fascista com relação às escolas italianas subsidiadas foi o envio de novos livros de texto permeados com a ideologia fascista. É nesse contexto que são aprovados e produzidos os dois volumes de Letture di Religione de autoria de Giuseppe Fanciulli.

A aprovação, a produção, o envio e a circulação de livros de leitura religiosa para escolas italianas no exterior não é um fato comum em tempos anteriores ao Fascismo. Eles são produto derivado da aproximação entre Igreja Católica e Estado fascista. Não se trata de incorrer em generalizações considerando que todos os que integravam a Igreja Católica aderiram ao Fascismo ou vice-versa, mas de considerar que "os católicos receberam relativamente bem o Fascismo inicialmente, se entusiasmaram com ele quando do Tratado de Latrão e perderam um pouco do seu encanto quando do caminho totalitário, racista e de aliança com a Alemanha nazista" como afirma Bertonha (2001, p. 354). O Fascismo representava disciplina, ordem, justiça social. Cabe recordar que a simpatia do Papa Pio XI por Mussolini e pelo Fascismo facilitaram o acordo estabelecido em 1929, o Pacto Lateranense. Catolicismo e Fascismo que eram contrários ao liberalismo e à expansão comunista, uniram-se, mas isso não se deu de modo simples e unívoco. O reconhecimento da religião católica como religião do Estado Italiano permitiu que o Fascismo dispusesse da Igreja e suas escolas, jornais e paróquias. Não foi um processo uniforme, mas o conservadorismo de muitos católicos promoveu as aproximações. Como o próprio Mussolini sinalizou, o catolicismo podia ser utilizado para a expansão italiana, leia-se, fascista. Afirma Giron, ao analisar a relação entre fascismo e catolicismo:

[...] ocorreu uma troca entre o fascismo e o papado, a Igreja recebeu os favores do reconhecimento de um Estado dentro do Estado Italiano e este recebeu o beneplácito daquela ao regime vigente. A troca favoreceu a Igreja que pode ampliar e remodelar seu império financeiro, enquanto Mussolini pode dispor da máquina da Igreja, tanto nas paróquias como no setor editorial, e dos meios de comunicação. (GIRON, 1994, p. 75).

A negociação que pôs fim à questão romana reconheceu o princípio de exercício de pleno poder e jurisdição soberana do Sumo Pontífice sobre o território do Vaticano, além disso, o Estado Italiano recompensou com uma soma em dinheiro as antigas províncias e bens perdidos pela Igreja Católica com a unificação italiana. Ainda, se estabelecia a concordata que regulava as relações entre Igreja e Estado. De outra parte, a Santa Sé dava por resolvida a questão romana em definitivo e reconhecia o Reino da Itália em sua formação e constituição. Como afirmam Cannistraro e Rosoli (1979) Igreja e Estado italiano fizeram concessões recíprocas.

A assinatura do Tratado de Latrão e o fim da Questão Romana foi intensamente comemorado entre os imigrantes e seus descendentes no Brasil. As páginas dos jornais permitem entrever a importância e vislumbrar as festividades celebrando o acordo. Observa-se que as negociações vinham sendo acompanhadas por diversos periódicos, especialmente aqueles publicados por congregações religiosas no Brasil. Como exemplo, 
La Staffetta Riograndense ${ }^{3}$ que, passados apenas dois dias da assinatura já divulgou nota festejando o tratado como observa-se na figura 1 :

Figura 1 - Nota divulgando a assinatura do Tratado de Latrão



Fonte: Jornal La Staffetta Riograndense, 13/02/1929, p. 2.

Na edição seguinte, o júbilo pela notícia do fim da Questão Romana foi destacado na primeira página, transcrevendo-se na íntegra, em italiano, o texto do tratado e suas principais ressonâncias. A seguir, pode-se observar na figura 2 a chamada jornalística de capa:

Figura 2 - Capa do Jornal La Staffetta Riograndense

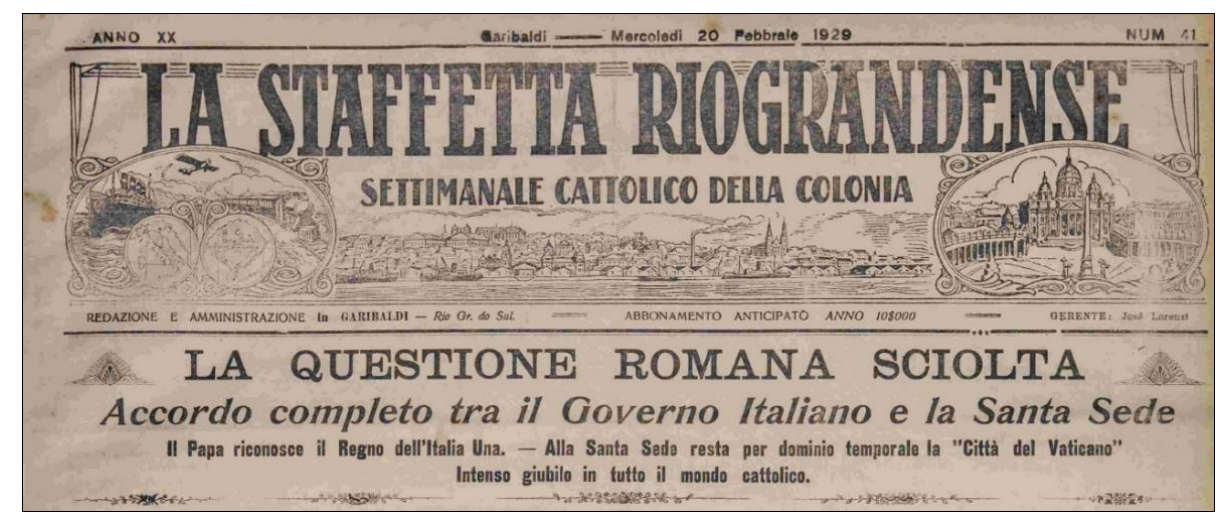

Fonte: Jornal La Staffetta Riograndense, 20/02/1929, p. 1.

A identificação de muitos clérigos com o Fascismo ${ }^{4}$ estava relacionada à luta contra o comunismo e o liberalismo, muitos deles tendo aderido ou admirado mesmo antes do fim da Questão Romana. No que se refere à Região Colonial Italiana do RS, Giron afirma que:

\footnotetext{
${ }^{3}$ La Staffetta Riograndense - jornal católico semanal da colônia. Redação e administração em Garibaldi, RS. Gerente: José Lorenzi. Sobre esse jornal consultar Valduga (2007).

${ }^{4}$ Consulte-se Cannistraro e Rosoli (1979), Sale (2011), Gaudio (1995) e Sani (2004) para a relação entre escola, Igreja e Fascismo na Itália.
} 
Mesmo antes de 1929, quando foi assinado o Tratado de Latrão, a influência da Itália fascista se fez sentir junto ao clero. Em 1923, D. Pedro Rota, superior dos salesianos, traz as boas novas da "Jovem Itália". Em 1924, é eleito para a Intendência de Caxias o Dr. Celeste Gobatto, o que fez com que o clero se regozijasse: um verdadeiro fascista assume o governo de Caxias (GIRON, 1994, p. 88).

$\mathrm{Na}$ interpretação da mesma autora a Igreja Católica na Região Colonial Italiana do Rio Grande do Sul foi essencial na organização política e na organização dos imigrantes e "foi a instituição que mais promoveu o fascismo". (GIRON, 1994, p. 87). A criação da Diocese de Caxias, no Rio Grande do Sul, resultou do diálogo de representantes da comunidade (especialmente Celeste Gobatto) e dos padres da região colonial com o Vaticano e estava acima do desejo do próprio Arcebispo D. João Becker, como analisa Giron (pp. 87 - 93). Mas o Rio Grande do Sul não foi exceção. O Cardeal D. Sebastião Leme do Rio de Janeiro demonstrou em diversos momentos estima pela Itália e pelo Duce, assim como o próprio Arcebispo de Porto Alegre, D. João Becker (BERTONHA, 2001).

Para os imigrantes italianos e descendentes, especialmente aqueles que viviam mais afastados, em áreas rurais, o clero foi um dos mais potentes portadores e difusores dos ideais fascistas. Além disso, é preciso considerar como afirma Valduga (2007, p. 157) que o Fascismo se apresentou como o "bastião da moralidade e operosidade e congratula-se com os feitos de seus filhos no exterior, exemplo máximo do valor de sua gente". Além disso,

O ufanismo era um sentimento novo e gratificante, os desvalidos imigrantes apátridas perceberam no seu trabalho um sentido maior e reconhecido pela pátria. Os imigrantes passam de colonos desconhecidos a símbolo do trabalho útil e produtivo. A Itália abria os braços para seus filhos de há muito esquecidos, e estes a reconheciam como pátria e se reconheciam como italianos. (GIRON, 1994, p. 109).

Trento (1989), Giron (1994) e Bertonha (2001) concordam que a adesão ao Fascismo se fez de modo mais amplo em meio à classe média e à burguesia. Para a imensa maioria, como refere Trento (1989) a admiração ao Duce pode ter sido maior do que a compreensão do Fascismo como projeto e ação político-ideológica já que Mussolini representou uma discursividade e também uma prática de valoração dos emigrados, da "grande Itália" e que "teve um peso não desprezível a função propagandística" (TRENTO, 1989, p. 304). Assim, a italianidade, como sentimento de identificação, de base para o processo identitário, foi com frequência tomado como equivalente ao Fascismo.

Envio de folhetos, livros, exibição de filmes, conferências, festividades, fundação do Instituto Ítalo-Brasileiro de Alta Cultura no Brasil, financiamento de viagens de jornalistas brasileiros para conhecer os 'feitos da Itália fascista' são alguns dos propagadores culturais elencados por Bertonha (2001) na difusão do Fascismo. Além disso, encenar obras italianas e em italiano em teatros importantes como o Municipal de São Paulo, apesar das poucas turnês de companhias italianas de prestígio, em 1929, Trento (1989) reporta o caso da Ruggiero Ruggieri. Outro intento cultural foi a criação da editora Sociedade Editora Latina por Rubbiani e Stevanoni destinada a publicar em italiano ou português, ou em ambas. (Trento, 1989). Para Bertonha "no que se refere ao Brasil, a documentação italiana revela um interesse relativamente baixo do Fascismo em difundir suas obras e sua doutrina entre os brasileiros" (2001, p. 272) com relação 
especialmente aos anos 20 do século XX. Para o mesmo autor, nos anos 30 "essa situação se modificou substancialmente e o esforço para a difusão do Fascismo cresceu de maneira notável" (BERTONHA, 2001, p. 274). A Sociedade Dante Alighieri deveria despontar como líder da propaganda fascista, mas em 1937 contava com apenas 150 inscritos na cidade de São Paulo e para Trento (1989, p. 299) "nem mesmo no passado jamais deixara grandes traços de si”.

Houve propaganda do Fascismo junto aos imigrantes e descendentes, especialmente pelos italianos imigrados após a Primeira Grande Guerra que, juntamente com os cônsules, lideraram a fundação de jornais ${ }^{5}$, a organização de festividades e celebrações, os programas de rádio, os fascios $^{6}$, os dopolavoro ${ }^{7}$, a abertura (ou reorganização) de escolas, o oferecimento de cursos de língua e cultura italiana, os espetáculos teatrais e musicais, enfim todo um aparato que, como afirma Trento buscou sensibilizar para a pertença aos 'italianos no exterior'

Além da tentativa de manter viva a italianidade e de inculcar uma ideologia nos filhos dos italianos, os esforços da mãe-pátria no período entre as duas Guerras foram dirigidos no sentido de garantir uma maior presença intelectual, capaz de influenciar a cultura local, seja através de uma difusão mais ampla da produção italiana, seja enviando professores universitários, seja, enfim, com a criação de escolas. (TRENTO, 1989, p.299).

Muitas das cerimônias e atividades coletivas contaram com a presença de simpatizantes brasileiros já que "salvo raras exceções, a classe política brasileira foi bastante indulgente em relação ao regime" (TRENTO, 1989, p. 305).

Olhar para a produção e circulação de livros enviados para o Brasil e que tinham intuito de difundir e conformar um ideal de 'italiano no exterior', de educa-lo para o trabalho e a religiosidade que eram as palavras de ordem da italianidade, agora diretamente relacionada com o Fascismo, provoca a observar o autor das duas obras em foco nesse texto: Giuseppe Fanciulli.

\section{2- Giuseppe Fanciulli: o autor e suas obras}

Um autor rapidamente esquecido afirma Montino (2009) em seu estudo sobre Fanciulli. Mas um autor que se dedicou intensamente à literatura infanto-juvenil, em tons "serenos e doces", produtor de uma vasta obra comprometida "com uma ideologia nacionalista para a qual havia ofertado sem reservas a sua caneta, ligando-se posteriormente ao fascismo" e por meio dessa adesão, passando a compor o conjunto de intelectuais que "magnificaram o regime e o seu Duce, e que aderiram, para além da ideologia, à ideia conservadora de Pátria que o nacionalismo havia fortificado a partir da Grande Guerra". (MONTINO, 2009, p. IX). No caso específico de Fanciulli, a sua fé católica permeou grande parte de suas atividades seja como escritor ou jornalista. E como reconhece Montino (2009) Pátria e Fé foram alicerces centrais de seu pensamento intelectual.

\footnotetext{
${ }^{5}$ Como exemplo, observe-se que o cônsul de Porto Alegre, Mario Carli fundou o jornal La Nuova Italia e o imigrante tutelado, engenheiro agrônomo, Adolfo Randazo fundou em Caxias o Il Giornale dell'Agricultore.

${ }^{6}$ Fasci all'estero - grupos que lideravam a organização da propaganda e difusão da ideologia fascista nas comunidades italianas do exterior, tentando cooptá-las. Desenvolviam também atividades assistenciais, culturais, cerimônias de defesa da italianidade e do fascismo.

${ }^{7}$ Dopolavoro all'estero eram associações voltadas aos operários que no exterior converteram-se em "meio muito eficaz de aproximar, via recreação, esporte e cultura, os italianos do exterior ao fascismo." (BERTONHA, 2001, p. 46).
} 
Giuseppe Gaetano Giulio Fanciulli ${ }^{8}$ nasceu aos oito de março de 1881 em Firenze. Seus pais eram Giovanni e Enrichetta Guidotti. Ele perdeu a mãe aos sete anos, permanecendo sob os cuidados de duas tias. Graduou-se em Filosofia no Régio Instituto de Estudos Superiores Práticos e de Aperfeiçoamento em 1906, aos 25 anos. No mesmo ano, graduou-se em Direito. Em 1909 obteve atestado para docência pela Universidade Popular de Firenze. Estudioso de Psicologia, em 1929, obteve livre docência em Psicologia pela Universidade de Firenze e também de Milão (Montino, 2009). Publicou artigos e obras com temáticas vinculadas à vida emocional da infância. Iniciou a carreira profissional como jornalista em 1906 e, em diferentes jornais e com diversas funções (correspondente, redator, diretor, colaborador...), esteve ao longo da vida ligado à atividade jornalística. Foi decisiva a experiência no Giornalino della Domenica, dirigido por Luigi Bertelli, conhecido como Vamba. Para Montino (2009), o trabalho jornalístico para a infância de Fanciulli foi o que o levou à literatura infantil.

Giancane (1994) considera o conjunto da obra de Fanciulli, com mais de uma centena e meia de livros, uma das maiores contribuições para a literatura infantil italiana. Em direção próxima, Montino (2009, p. XIV) avalia que Fanciulli foi "uma das vozes mais difundidas e penetrantes da vocação pedagógica da literatura para as crianças na primeira metade do novecentos". No conjunto, a obra de Fanciulli foi elaborada em torno de valores da nação, do interclassismo, do paternalismo, dos bons sentimentos, e de uma visão de mundo urbana e burguesa (MONTINO, 2009). A modernidade de Fanciulli esteve nas várias frentes que mobilizou também para atuar, pois publicou livros, escreveu para jornais, para teatro e participou de programas de rádio. Montino (2009, p. XV) afirma que a "vasta obra pedagógica posta a serviço de uma certa ideia de italianidade, e primeiro ainda de uma certa necessidade novecentista de educar as massas, de disciplinar a partir da infância, onde a literatura infanto-juvenil foi um dos dispositivos mais potentes e eficazes." Com relação a sua intensa produção, apresento algumas capas de livros de Fanciulli:

Figura 3 - Algumas capas de livros publicados por Fanciulli no período fascista

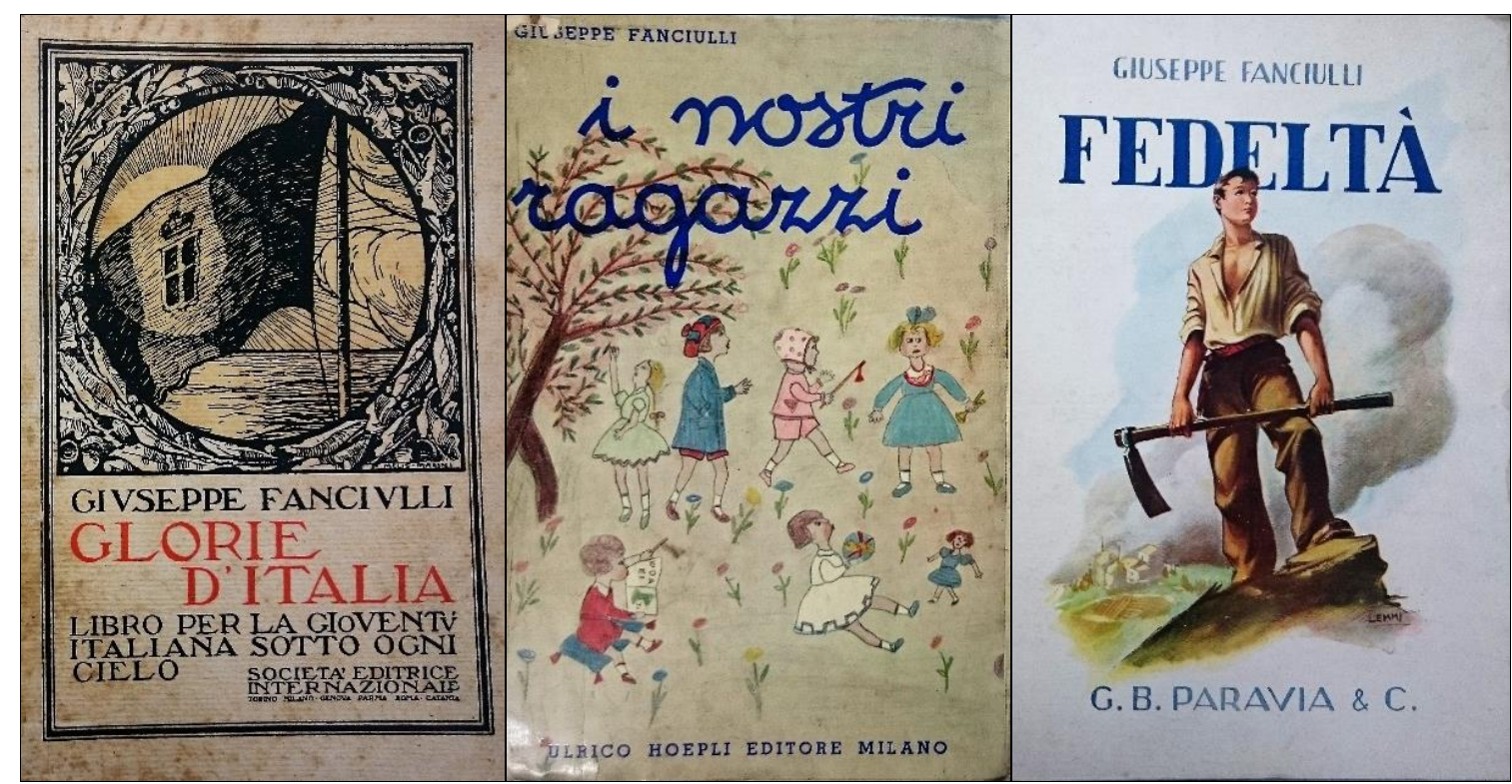

Fonte: reprodução da autora a partir do acervo de Centro de Documentazione e Storia dello Libro Scolastico e della Letteratura per l’Infanzia, UniMC.

\footnotetext{
${ }^{8}$ Uma nota biográfica sobre Giuseppe Fanciulli pode ser consultada também na Enciclopédia Treccani, disponível em: http://www.treccani.it/enciclopedia/giuseppe-fanciulli_(Dizionario-Biografico)/ acesso em 18/12/17.
} 
A modo de exemplificação, Fanciulli em Glorie d'Italia (1929) escreve um livro dedicado aos jovens em que narra a história da Itália, com diversos momentos de edificação patriótica. Uma breve apresentação é escrita por Piero Parini, fervoroso fascista que no ano da publicação desse livro era Secretário dos Fascios all Estero e também, em seguida, assumiu a Direção Geral dos Italianos e Escolas no Exterior. Para Parini, o livro de Fanciulli "conta a história milenar e exalta os homes que honraram com suas empresas famosas, com as armas, a ciência, a coragem aventureira, as belas artes e a indomável fé religosa" e conclui afirmando "a Itália viverá eternamente e ainda dominará" (PARINI, in FANCIULLI, 1929, s/p). Glorie d'Italia foi ilustrado com xilogravuras por Marini Melis 9 .

A segunda capa, do livro "I nostri ragazzi" foi publicado em 1937 e desenvolve um conjunto de considerações e orientações relativas ao desenvolvimento infantil, a importância do cuidado e processo educativo. Já a terceira capa, estampa o livro Fedeltà, um romance para rapazes, que foi ilustrado por Roberto Lemmi ${ }^{10}$. Mas a obra de Fanciulli foi extensa, em catálogo de 1935 da Editora Bemporad, "Edizioni per la Gioventù" a obra de Fanciulli publicada por essa editora ocupar 3 páginas, conforme a figura a seguir:

Figura 4 - Páginas do catálogo da Editora Bemporad com obras de Fanciulli, 1935

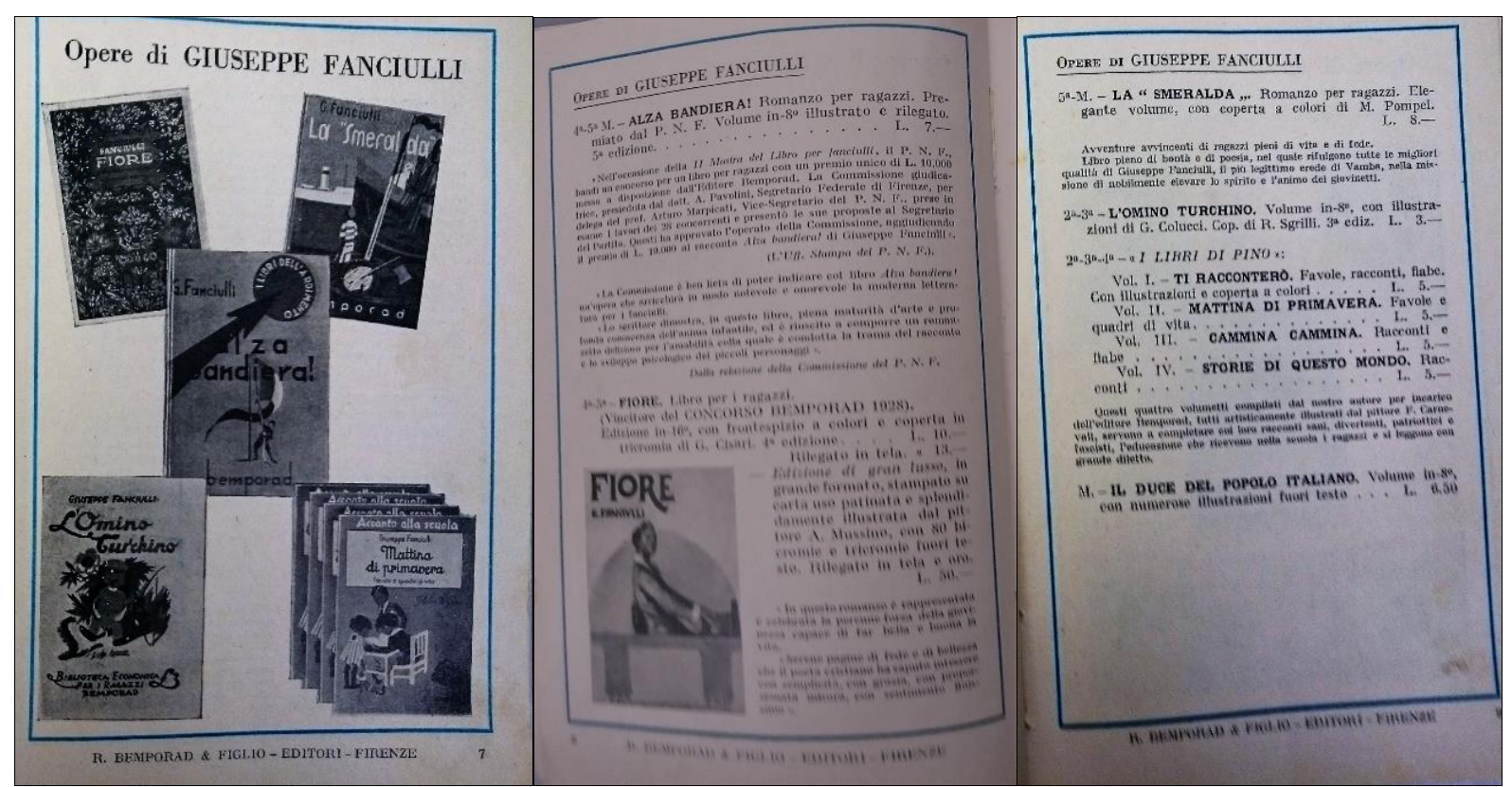

Fonte: reprodução da autora a partir de BEMPORAD, 1935, p. 06, 07 e 08.

Em sua intensa e extensa produção, Fanciulli usou pseudônimos como Chichibio, mas ficou conhecido como Maestro Sapone. Ele publicou e teve diversos livros de História, de leitura, de testes para escolas de Ensino Médio e também os que aqui são analisados, de

\footnotetext{
${ }^{9}$ Felice Marini Melis nasceu em 18 de dezembro de 1871 em Cagliari, filho de burgueses, Enrico Melis e Annunziata Marini. Concluiu estudos em arte em Roma em 1902. Em 1906 casou-se com Ersilia Meloni. Abriu uma escola de artes, percorrendo intensa e reconhecida carreira como pintor e ilustrador. Faleceu em Cagliari, aos 30 de abril de 1953. Ver mais em http://www.treccani.it/enciclopedia/felice-melis-marini_(DizionarioBiografico) acesso em 24/01/2018.

${ }^{10}$ O ilustrador Roberto Lemmi nasceu em Florença em 1901 e faleceu, também em Florença, em 1971. Frequentou a Academia de Bellas Artes de Florença e fez uma carreira reconhecida por se um naturalista apaixonado. Desenvolveu inúmeros trabalhos para empresas e editoras, dentre outros. Ver mais em: https://www.cacciando.com/lettere-e-foto/letteratura/libri-d-arte-art/item/1688-roberto-lemmi.html acesso em $24 / 01 / 2018$
} 
ensino religioso, aprovados pelas comissões de avaliação de livros para as escolas italianas da Itália e no exterior. Fanciulli foi casado com Marialù Cadeddu e faleceu em 16 de agosto de 1951, aos setenta anos, em Castelveccania, província de Varese.

\section{3 - Letture di Religione: a produção e a circulação}

O Decreto Régio $\mathrm{n}^{\circ} 737$, de 11 de março de 1923 , estabeleceu as normas para adoção de livros de texto nas escolas elementares e populares, públicas e privadas da Itália. O Diretor Geral da Instrução Elementar Giuseppe Lombardo Radice, juntamente com professores, funcionários ministeriais e homens "de cultura" compunham as comissões de seleção que em junho de 1923 divulgavam as primeiras relações de livros aprovados (ASCENZI e SANI, 2005). Para o ano escolar de 1924-25 os títulos Gente Nostra, Creature e Como sono Felice todos de Giuseppe Fanciulli foram recomendados para bibliotecas escolares e também para serem distribuídos aos alunos das escolas italianas como premiação. Além desses, os dois volumes de Letture di Religione escritos e compilados por Giuseppe Fanciulli foram aprovados. No entanto, cabe ressaltar que as edições analisadas são de 1932 e 1935 e as capas podem ser observadas na figura 5.

Figura 5 - Capas dos livros Letture di Religione

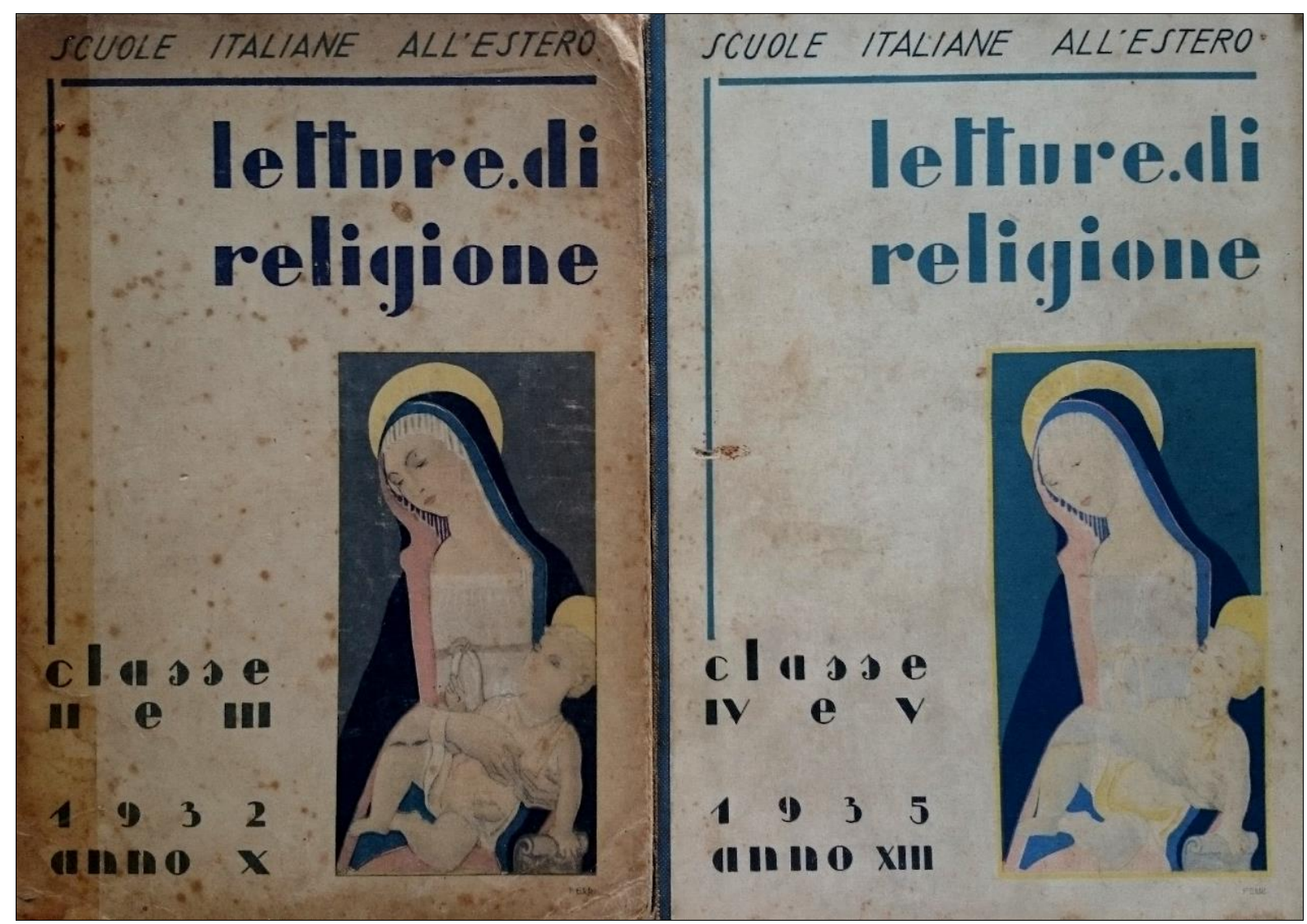

Fonte: acervo pessoal da autora. 
As capas são exatamente iguais. As duas obras de Letture di Religione contavam com páginas inteiras ilustradas por Beryl Tumiati ${ }^{11}$. Da mesma forma, as contracapas são idênticas, mudando apenas a identificação dos volumes e as classes a que se destinavam. Observe-se a figura 6:

Figura 6 - Contracapa dos livros Letture di Religione

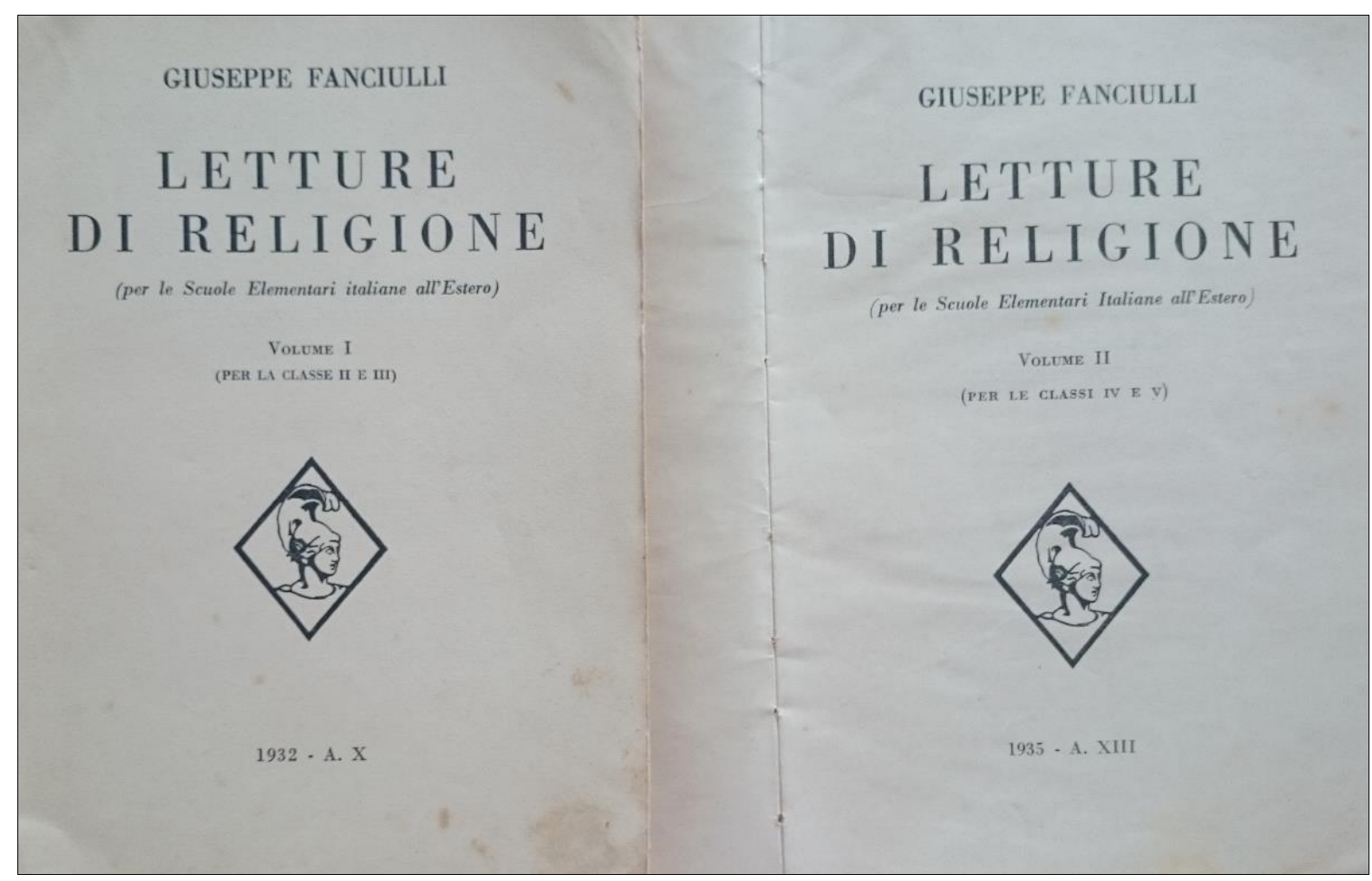

Fonte: acervo pessoal da autora.

Observe-se o desenho que acompanha a contracapa de ambos os livros representa os elmos usados pelos centuriões romanos. É recorrente o argumento de que a "nova Itália" Fascista é a retomada do grande Império Romano, do qual todos os italianos são herdeiros.

Nas obras analisadas, o primeiro livro, dirigido à II e III classe pertenceu à Nicolino Murino, estudante do Instituto Manzoni de São Paulo, conforme figura 7 No segundo volume, dirigido para IV e V classe não consta assinatura.

Figura 7 - Assinatura interna - Letture di Religione

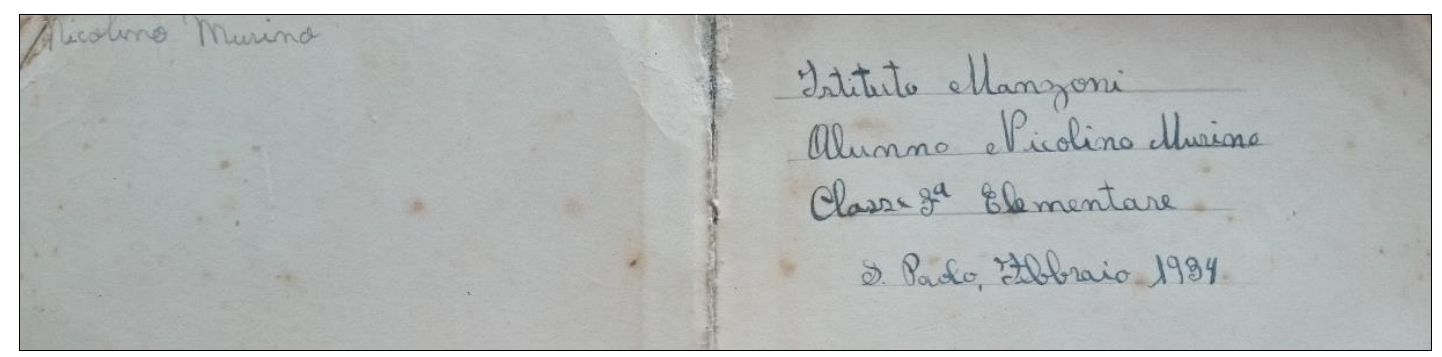

Fonte: acervo pessoal da autora.

${ }^{11}$ Não foi possível localizar maiores informações sobre esse ilustrador, apenas que ele ilustrou outras obras de Fanciulli - Creature (1918) e I Grandi Navigatori Italiani (1931). E que participou entre maio e junho de 1917 da Mostra Sarda em benefício aos órfãos sardos juntamente com outros importantes ilustradores italianos do primeiro novecentos. 
Analisando a materialidade dos livros é possível perceber uma mudança significativa no que tange ao papel, às ilustrações e ao uso de cores dos livros didáticos italianos produzidos nas décadas de 1920 e 1930, se comparados com os livros enviados pelo governo às escolas italianas ao final do século XIX e primeiras décadas do século XX. Papel de qualidade superior, uso de cores e ilustrações belíssimas, presentes com maior frequência num projeto gráfico arrojado para a época, decorrente de investimentos elevados são marcas possíveis de serem visualizadas nos livros. Como constatou Galfré (2005, p. 27) "[...] é propósito do governo - conforme o comunicado oficial - dar ao livro não apenas as vestes, mas também a alma fascista". Os livros foram portadores de uma proposta educativa ligada à ideologia fascista que não deixou de considerar e construir a relação entre pátria (fascista), conduta moral, religião e família.

O volume I do livro Letture di Religione tem 111 páginas. Destas, 40 são dedicadas à segunda classe e 52 páginas para a terceira classe. Na segunda classe os temas abordados estão relacionados à criação do mundo, aos dez mandamentos, aos sacramentos, às orações como Pai Nosso, Ave Maria, Gloria ao Pai, Creio, algumas poesias, parábolas recontadas a partir da Bíblia e perguntas simples acompanhadas de respostas. As imagens são de página inteira e mais frequentes. Pequenas poesias e cantos estão presentes. Da mesma forma, na parte dedicada à terceira classe inicia explicando quem é Deus, quem são os anjos, momentos da vida de Jesus, de sua infância, juventude e idade adulta, destacando-se os milagres, sua atenção para com as crianças, sua morte e ressureição. Entre as diversas ilustrações de Beryl Tumiati, muitas de página inteira, coloridas, observe-se algumas representadas na figura a seguir:

Figura 8 - Ilustrações de Beryl Tumiati

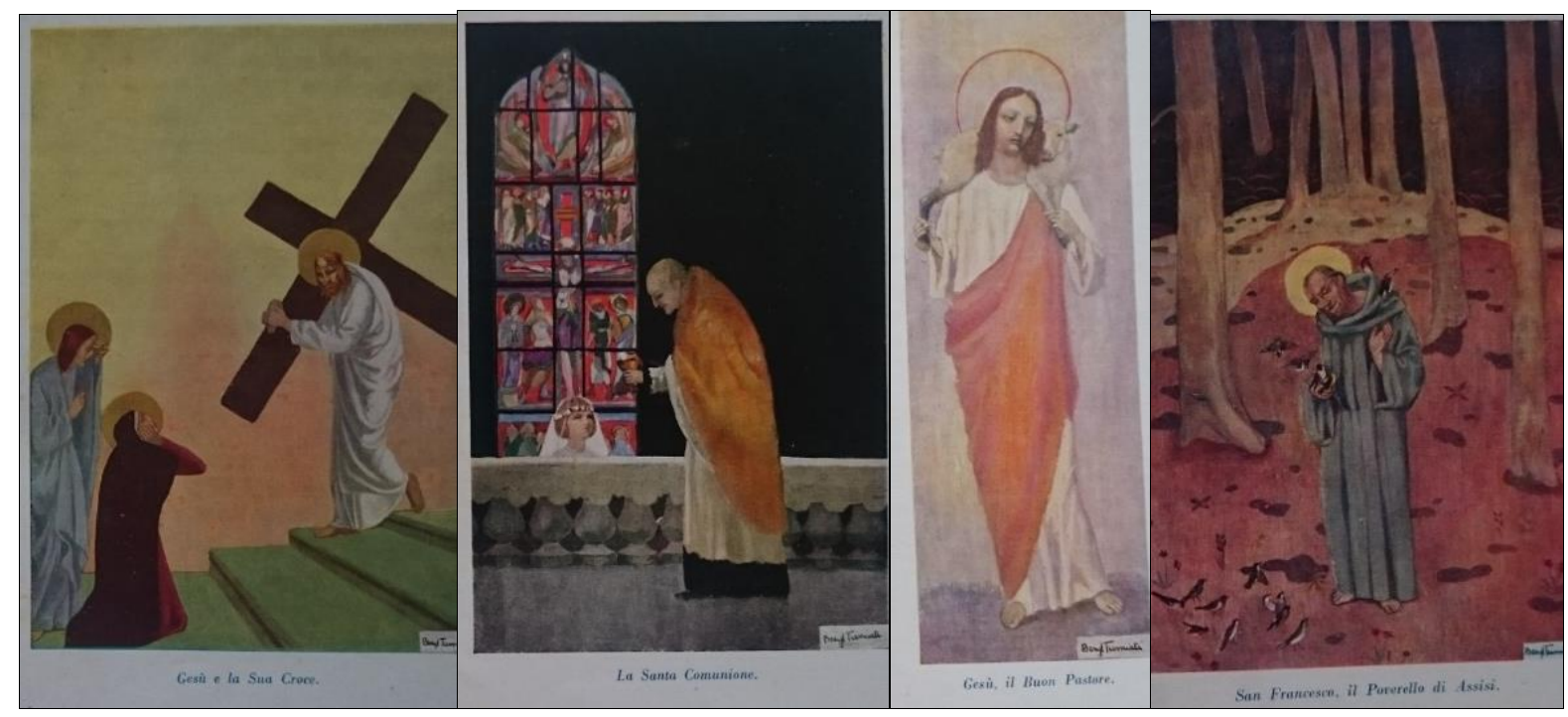

Fonte: acervo pessoal da autora.

As temáticas são abordadas em textos breves, com frases curtas e diretas. Há pequenas poesias, perguntas seguidas de respostas a exemplo do exposto no Catechismo della Dotrina Cristiana. Como manifesto já nas primeiras páginas de ambos os volumes escritos por Fanciulli consta que "as perguntas e respostas estampadas em cursivo e negrito, ao término de alguns capítulos, são relatados no Catechismo della Dottrina Cristiana, publicado por ordem de Sua Santidade Papa Pio X” (FANCIULLI, 1932, p. 08). 
O volume II do livro Letture di Religione tem 159 páginas, sendo que 42 delas são dedicadas à quarta classe e 98 para a quinta classe. Nesse volume a quantidade de texto é maior, diminuindo-se inclusive o tamanho da fonte utilizada. Outra diferença, em relação ao volume anterior, é que agora são feitas pequenas inserções de autores italianos. Por exemplo, entre as páginas 17 e 18 temos a poesia "Deus vê e sabe tudo" do historiador italiano Cesare Cantù. Outros italianos como Alessandro Manzoni, Contardo Ferrini, Santo Agostinho e Dante Alighieri tem pequenos trechos ou poemas transcritos.

No que se refere aos conteúdos abordados, na quarta classe estão as orações para manhã e noite, os dez mandamentos, as histórias bíblicas e os textos para a Primeira Comunhão. A quinta classe inicia pelo estudo da Liturgia e ritos da Missa. Após os sacramentos do Batismo, da Eucaristia, do Crisma, do Matrimônio e da Extrema Unção são destacados. Para, ao final, apresentar biografias dos "grandes santos italianos", entre eles São Bento, São Francisco de Assis, Santo Tomás de Aquino, Santa Catarina de Siena, Santa Clara e muitos outros, como São Luiz Gonzaga - o santo dos jovens, Dom Bosco e São Carlos de Borromeo. Para finalizar, Fanciulli apresenta 'A Madonna' Maria Imaculada. O texto inicia apresentando o milagre, também referindo à Itália, de 'Nostra Signora di Gonare', da Sardenha, que salvou os tripulantes e o príncipe de uma tempestade. Fanciulli escreveu "Maria ajudou os navegadores; e todos nós somos navegadores no mar da vida; se chega e se vai, na viagem encontramos deliciosos dias de fartura e outros de grande tormenta e dificuldade" (1934, p. 149). E aclamava para implorar o agradecer, nos bons e maus momentos, para que se contasse com a intercessão de Maria. E um pequeno trecho da Divina Comédia acompanhada de interpretação de Fanciulli e da ilustração vista na figura a seguir, concluíam essa parte:

Figura 9 - Imagem de Nossa Senhora Imaculada - A Madonna

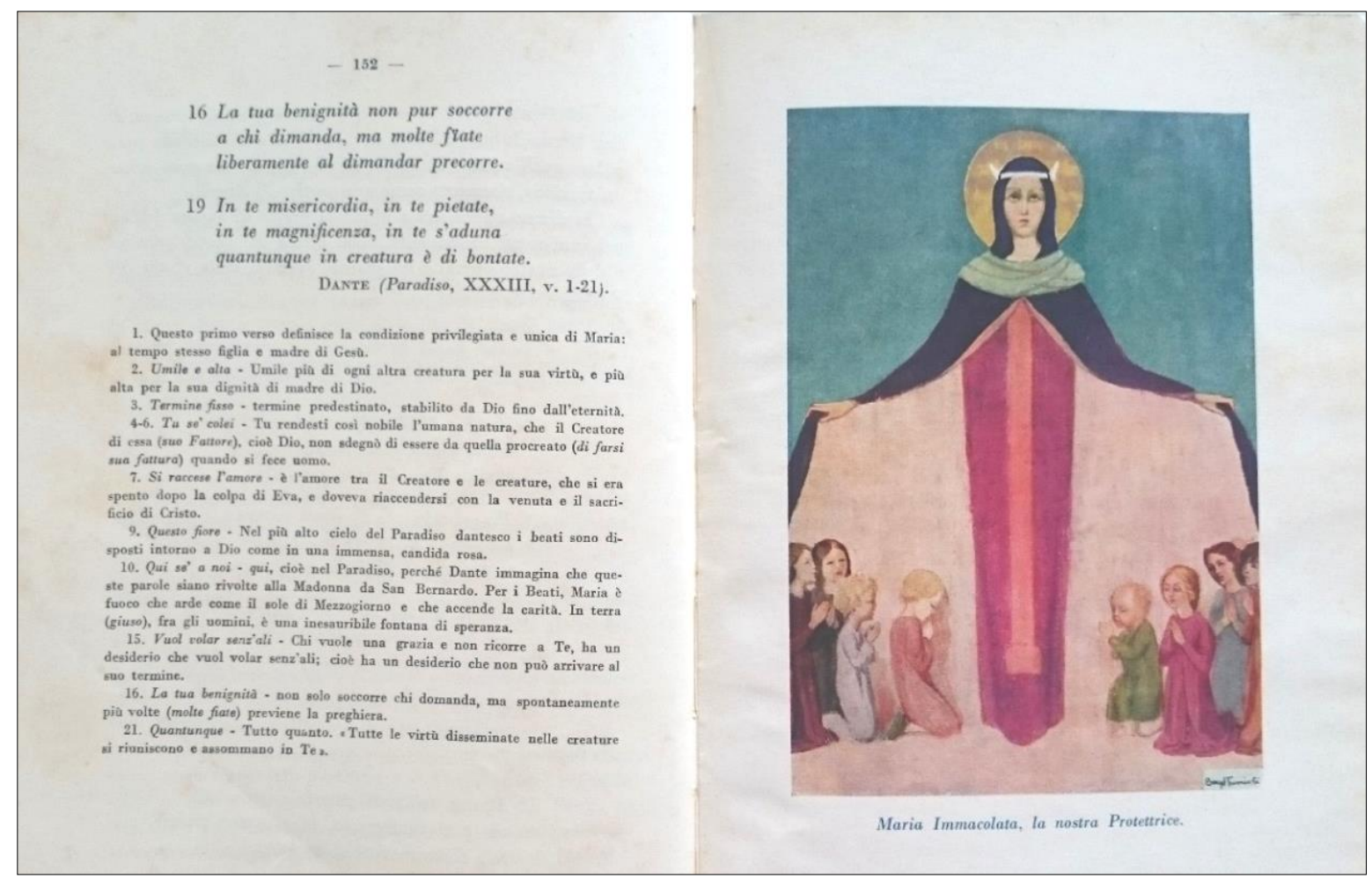

Fonte: Acervo pessoal da autora. 
Desse modo, Letture di Religione apresenta páginas recheadas de orientações religiosas, histórias e outros textos que põem em relevo o respeito às autoridades, a centralidade do trabalho, a preservação da família e das tradições. Lições de moralidade, de que atitudes eram desejadas são frequentes: "Muitos homens são bons: rezam para Deus, amam a justiça, fazem caridade, se preparam para receber um dia o prêmio eterno." (FANCIULLI, 1932, p. 54). Esse prêmio "se chama Paraíso e o castigo é o Inferno" (FANCIULLI, 1932, p. 30). Assim, as crianças e jovens foram instruídos para assumir postura de fé, professando valores morais, rezando e "evitando todas as tentações" (idem, p. 104).

Cabe, ainda, ressaltar que em ambos os volumes consta o "imprimatur" concedido em agosto de 1931 pelo arcebispo Joseph Palica ${ }^{12}$ (1869 - 1936). "Cum servata sint omnia quae servanda erant" (FANCIULLI, 1932, p. 111) ou seja, com observância de todas as coisas que deviam ser observadas. O registro mantido na produção do livro pode ser observado na Figura 10:

Figura 10 - Licença para impressão dos livros Letture di Religione

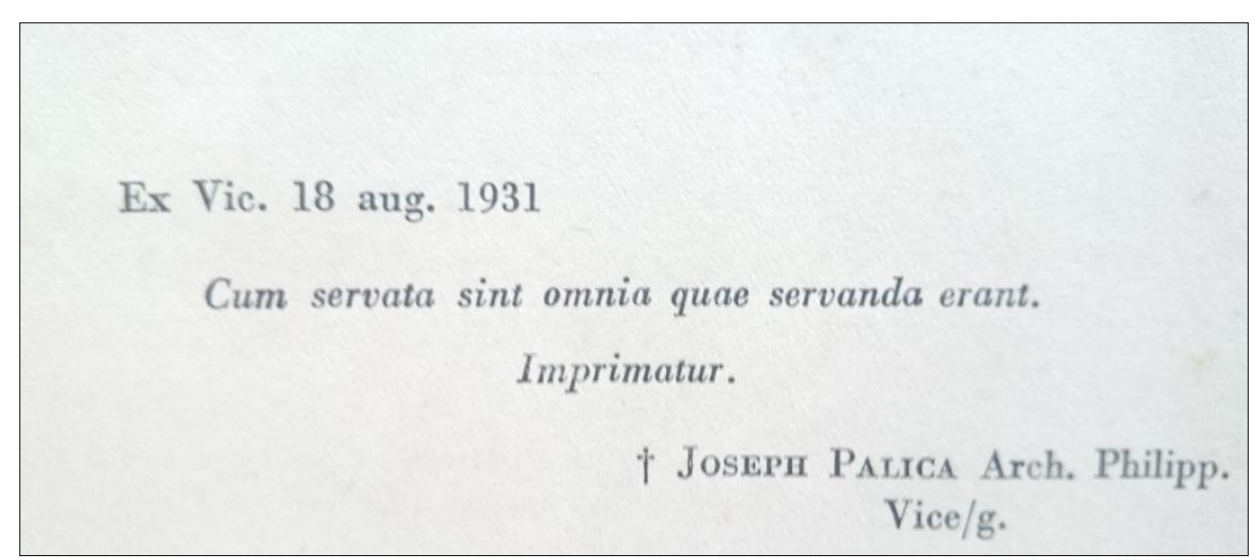

Fonte: acervo pessoal da autora.

A publicação de Giuseppe Fanciulli, Letture di Religione, foi duplamente aprovado - pelo Estado Fascista e pela Igreja Católica para ser enviado para as escolas italianas no exterior. Por fim, cabe mencionar que os livros foram impressos na gráfica A. Mondadori, em Verona, como tantas outras obras publicadas pelo Estado Italiano fascista (ver mais em Galfré, 2005). Charnitzky (1996) afirma que como característica geral dos textos estava a "contínua politização dos temas, pelo entrelaçamento de conteúdos religiosos e políticos, culminando com a representação de Mussolini difundida também em inúmeras publicações não escolares - enviado por Deus para salvar a Itália." (CHARNITZKY, 1996, p. 406). No caso dos livros de Fanciulli analisados, se trata de difundir modos de ser e agir, para além de trechos bíblicos e orações, com uma seleção de textos de nomes importantes para a história da Itália e que escreveram sobre essa vinculação entre pátria e catolicismo. As histórias de vidas dos Santos apresentadas, também não são nada aleatórias, mas exemplares e estão vinculadas a essa perspectiva nacionalista de constituição do 'novo' italiano que respeitando hierarquias, cultuava valores e responsabilidades.

\footnotetext{
12 Joseph Palica ou Giuseppe Palica nasceu em 08 de outubro de 1869 em Roma. Em 18 de dezembro de 1892 foi ordenado padre em Roma, ali permanecendo. Aos 25 de abril de 1917 foi nomeado Arcebispo titular da cidade grega de Philippi. Faleceu aos 67 anos, aos 16 de dezembro de 1936. Ver em http://www.catholichierarchy.org/bishop/bpalica.html acesso em 07/02/16.
} 


\section{Considerações finais}

"O Paraíso é o prêmio de uma vida cristã" (Fanciulli, 1935, p. 153) e "como mais belo prêmio" só poderia ser obtido por aqueles que fossem leais, devotados ao bem de sua família e do próximo, "prontos a servir à Pátria com todas as suas forças", entusiasmados pela beleza da natureza e da arte, obedientes aos seus deveres. Capazes de resistir às tentações e seguir as normas instituídas. Um cristão que vivesse "essas regras seria o melhor filho, o melhor irmão, o melhor soldado, o melhor cidadão" (Fanciulli, 1935, p. 154). Era o que se esperava de um italiano no exterior - devotado duplamente ao catolicismo e ao fascismo. Mas a apropriação do conteúdo dos livros pode ter sido diversa, como nos alerta Chartier, ao afirmar que "[...] cada leitor, a partir de suas próprias referências, individuais e sociais, históricas ou existenciais, dá um sentido mais ou menos singular, mais ou menos partilhado, aos textos de que se apropria." (CHARTIER, 2009, p. 20).

As obras analisadas foram distribuídas no Brasil pelos consulados e agentes consulares. Foram utilizadas nas escolas étnicas por um lapso de tempo curto já que a maioria dessas escolas foram fechadas em 1938. No entanto, isso não significa que tenham sido deixados de lado. Pelo tema que abordavam, foram mantidos nas famílias e lidos pelas crianças e jovens, por orientação de pais e mesmo de alguns padres. A complexidade das dinâmicas e processos históricos vividos naquele momento entre a Itália e o Brasil, não podem ser esgotados num artigo. Mas é possível reconhecer que os livros constituem parte de uma cultura da infância alfabetizada, que buscam (con)formar processos identitários dos 'italianos no exterior', ordenando uma visão de mundo, um lugar no tecido social, modos de comportar-se, de ser e estar no mundo.

De outra parte, o autor das obras, como refere Montino (2009) produz uma leitura própria daquele momento histórico na relação entre fé e nacionalismo. Refere Montino que "a fé de Fanciulli, uma fé não convencional, mas profunda escolha de vida, sendo que não se pode reduzir a espiritualidade de um bom homem", pois vivendo naquele momento histórico, Fanciulli interpretou "um tipo preciso de catolicismo [...] nacional e também nacionalista [...] que não teme a guerra como instrumento de afirmação patriótica e de transmissão da civilidade" (MONTINO, 2009, p. 212).

Compreender os saberes produzidos e difundidos pelos usos de materiais didáticos vinculados ao ideal fascista, às políticas governamentais italianas voltadas para a dotação de materiais específicos para as escolas italianas no exterior, assim como a questão dos usos e dos sentidos simbólicos que esses objetos adquiriram no universo escolar é tema de relevância para a História da Educação. A presença de professores enviados pelo governo italiano, o envio de material escolar, especialmente livros didáticos e a propagação do discurso fascista nos espaços das escolas étnicas foi uma realidade. No entanto, as reações não foram exclusivamente do governo brasileiro a partir de medidas de nacionalização do ensino na década de 30 do século XX. Nas próprias comunidades ítalo-brasileiras a simpatia com o Duce e o regime fascista não foi uma uniformidade.

O artigo procurou contribuir para a compreensão da multiplicidade de processos de escolarização brasileiros, considerando sua diversidade étnica e cultural, a partir da análise de dois manuais didáticos de ensino religioso produzidos e enviados pelo Governo Italiano às escolas étnicas italianas no Brasil. 


\section{REFERÊNCIAS}

ASCENZI, A.; SANI, R. Il libro per la scuola tra idealismo e fascismo. Milano: Vita e Pensiero, 2005.

BEMPORAD, Editora. Edizioni per la Gioventù. Catalogo da R. Bemporad. Florença: R. Bemporad, 1935.

BERTONHA, J. F. O fascismo e os imigrantes italianos no Brasil. Porto Alegre: EDIPUCRS, 2001.

CANNISTARO. P.V. e ROSOLI, G.. Emigrazione, Chiesa e Fascismo. Lo scioglimento dell 'Opera Bonomelli (1922 - 1928). Roma: Edizioni Studium, 1979. https://doi.org/10.1086/ahr/86.1.170

CHARNITZKY, J. Fascismo e Scuola. La política scolastica del Regime (1922 - 1943). Flaorença: La Nuova Italia, 1996.

CHARTIER, R. Prefácio. In: CHARTIER, R. (org.). Práticas da leitura. $4^{\mathrm{a}}$ ed. São Paulo: Estação Liberdade, 2009b, p. 20.

CORREIO PAULISTANO. Diretor geral Flaminio Ferreira e gerente Edgard Nobre de Campos. Edição de 24/12/1927, p. 16.

CORREIO PAULISTANO, dirigido por Abner Mourão e com gerência geral de Edgar Nobre de Campos. Publicado na quarta-feira, 08/01/1930, p. 07.

CORREIO PAULISTANO, órgão do Partido Republicano Paulista. Redator-chefe José Carlos Pereira de Sousa, superintendente Antonio Hermann Dias Menezes. Ano LXXXII. Edição de 08/08/1936, no 24.661, p.04.

CORREIO PAULISTANO, órgão do Partido Republicano Paulista. Redator-chefe José Carlos Pereira de Sousa, superintendente Antonio Hermann Dias Menezes. Ano LXXXII. Edição de 24/12/1936, n 24.779, p.12.

CORREIO PAULISTANO, órgão do Partido Republicano Paulista. Redator-chefe José Carlos Pereira de Sousa, superintendente Antonio Hermann Dias Menezes. Ano LXXXIII. Edição de 01/01/1937, nº 24.785, p. 17.

FANCIULLI, G.. Letture di religione. Classe II e III (per le Scuole Elementari Italiane all’Estero). Vol I. Verona: A. Mondadori, 1932.

FANCIULLI, G.. Letture di religione. Classe IV e V (per le Scuole Elementari Italiane all'Estero). Vol II. Verona: A. Mondadori, 1935.

FANCIULLI, G. Glorie d'Italia: libro per la gioventu italiana sotto ogni cielo. Prefazione di Piero Parini. Turim: Societa Editrice Internazionale, 1929.

FANCIULLI, G. Fedeltà: romanzo per i ragazzi. Turim: G. B. Paravia \& C., 1942.

FANCIULLI, G. I nostri ragazzi. Milano: U. Hoepli, 1937.

GALFRÉ, M.. Il regime degli editori: libri, scuola e fascismo. Roma - Bari, Italia: Laterza, 2005. 
GAUDIO, A.. Scuola, Chiesa e Fascismo. La scuola cattolica in Italia durante il fascismo (1922 - 1943). Brescia: La Scuola, 1995. https://doi.org/10.5944/hme.7.2018.19389

GIANCANE, D.. Giuseppe Franciulli maestro della letteratura per l'infanzia. Una monografia. Bari: Levante Editori, 1994.

GIRON, L.S.. As sombras do Littorio. O fascismo no Rio Grande do Sul. Porto Alegre: Parlenda editora, 1994. https://doi.org/10.15448/1980-864x.1994.1.29095

JORNAL A GAZETA. Dirigido por Pedro da Motta Lima. Ano XXV. Edição de quarta-feira, 03/12/1930, no 7.446, p.12.

JORNAL LA STAFFETTA RIOGRANDENSE - settimanale cattolico della colonia. Editado em Garibaldi/RS.

LUCHESE, T. Â.. O processo escolar entre imigrantes no Rio Grande do Sul. Caxias do Sul: EDUCS, 2015.

LUCHESE, T. Â. (org.). História da Escola para imigrantes italianos e descendentes em terras brasileiras. Caxias do Sul: EDUCS, 2014.

LUCHESE T. Â. Em busca da escola pública: tensionamentos, iniciativas e processo de escolarização na Região Colonial Italiana, Rio Grande do Sul, Brasil. In: Cadernos de História da Educação. V. 11, $\mathrm{n}^{\mathrm{o}} \quad 2, \quad$ jul/dez. 2012, p. $667 \quad-\quad 679 . \quad$ Disponível em: http://www.seer.ufu.br/index.php/che/article/view/21718/11927 acesso em 08/02/16. https://doi.org/10.15448/1984-4301.2017.1.25075

MINISTERO DEGLI AFFARI ESTERI. Annuario dele scuole italiane all'estero: governative e sussidiate. Roma: Tipografia del Ministero degli Affari Esteri, 1908. https://doi.org/10.2307/2608335

MONTINO, D. Le tre Italie di Giuseppe Faciulli. Educazione e letteratura infantile nel primo Novecento. Torino, Italia: SEI Frontiere, 2009.

PARLAGRECO. C. Le Scuole Italiane. In: Fanfulla.. Il Brasile e gli italiani. Firenze: R. Bemporad \& Figlio, 1906, p. 796 - 810.

SALE, G. La Chiesa di Mussolini. I raporti tra fascismo e religione. Milano: Rizzoli, 2011.

SALVETTI, P. Le scuole italiane all'estero. In: Bevilacqua Piero; De Clementi, Andreina e Franzina, Emilio (orgs.). Storia Dell'Emigrazione Italiana. II Arrivi. Roma, Italia: Donzelli Editore, 2009. https://doi.org/10.1017/s1353294400014149

SANI, R. 'La Civiltà Cattolica' e la politica italiana nel secondo dopoguerra (1945 - 1958). Milano: Vita e Pensiero, 2004.

TRENTO, A. Do outro lado do Atlântico: um século de imigração italiana no Brasil. São Paulo: Nobel, 1989.

VALDUGA, G.. Paz, Itália, Jesus. Uma identidade para imigrantes italianos e seus descendentes: o papel do jornal Correio Riograndense (1930 - 1945). 205fl. Porto Alegre: PUC/RS, 2007. (Dissertação em História). 